\title{
Infecção por pox vírus e Aspergillus fumigatus em Bubo virginianus (Coruja jacurutu) ${ }^{1}$
}

\author{
Joanna V.Z. Echenique 2 , Paulo M. Bandarra33, Rodrigo K. Brauner ${ }^{3}$, Mauro P. \\ Soares ${ }^{4 *}$, Marco A.A. Coimbra ${ }^{3}$ e Ana Lucia Schild ${ }^{4}$
}

\begin{abstract}
Echenique J.V.Z., Bandarra P.M., Brauner R.K., Soares M.P., Coimbra M.A.A. \& Schild A.L. 2016. [Avipoxvirus infecction in Bubo virginianus (great horned owl).] Infecção por pox vírus e Aspergillus fumigatus em Bubo virginianus (Coruja jacurutu). Pesquisa Veterinária Brasileira 36(7):630-633. Laboratório Regional de Diagnóstico, Faculdade de Veterinária, Universidade Federal de Pelotas, Campus Capão do Leão s/n, Pelotas, RS 96010-900, Brazil. E-mail: gmpsoares@gmail.com

This paper describes a case of mixed infection by pox virus and Aspergillus fumigatus in Bubo virginianus (Owl Jacurutu). An adult male Bubo virginianus was referred to the Núcleo de Reabilitação da Fauna Silvestre, Instituto de Biologia, Universidade Federal de Pelotas (NURFS/CETAS/UFPEL). The owl was active and had a good body condition but with flight disability. After three days of their admission at NURFS the owl developed crusty and verrucous lesions at the dorsal surface of their feet. Also it had nodes on the left eyelid and cera with the same aspect. The owl died 15 days after its arrival. Necropsy and histopatological examination were carried out. The warty lesions had hyperplasia of the epithelium and intracytoplasmic Bollinger-like inclusion bodies in the basal, spinal, granulosa layer and cornea. Viral particles characteristic of pox viruses were shown by electron microscopy. This case includes Bubo virginianus as a host of the avipoxvirus. There were also a mononuclear inflammatory cell infiltrate and bacterial colonies in the dermis. In the lugs, there was congestion and presence of granulomas with intralesional fungal hyphae. With the Grocott stain those structures showed dichotomous branching which was later identified in mycological culture as characteristic for $A$. fumigates. The diagnosis of avipoxvirus infection can contribute to studies related to the occurrence of this disease in free-living populations and as auxiliary information for the management and conservation of this raptor species. It is also suggested to include the use of X-rays in rehabilitation center protocols as screening test to diagnose aspergillosis in birds of prey with good body condition but inability to fly.
\end{abstract}

INDEX TERMS: Avipoxvirus, fowlpox, Aspergillus fumigatus, aspergillosis, Bubo virginianus, great horned owl.

RESUMO.- Este trabalho descreve um caso de infecção mista por pox vírus e Aspergillus fumigatus em Bubo virginianus (coruja jacurutu). A ave, um macho adulto, foi encaminhada ao Núcleo de Reabilitação da Fauna Silvestre do Instituto

\footnotetext{
${ }^{1}$ Recebido em 18 de fevereiro de 2016. Aceito em 5 de abril de 2016.

${ }^{2}$ Graduanda da Faculdade de Veterinária, Universidade Federal de Pelotas (UFPel), Campus Capão do Leão s/n, Pelotas, RS 96010-900, Brasil. Bolsista de IC FAPERGS.

${ }^{3}$ Núcleo de Reabilitação da Fauna Silvestre, UFPel, Campus Capão do Leão s/n, Pelotas, RS 96010-900.

${ }^{4}$ Laboratório Regional de Diagnóstico, Faculdade de Veterinária, UFPel, Campus Capão do Leão s/n, Pelotas, RS 96010-900. *Autor para correspondência: gmpsoares@gmail.com
}

de Biologia da Universidade Federal de Pelotas (NURFS/ CETAS/UFPEL). Apresentava bom estado corporal, estava ativa, porém com incapacidade de voo. Após três dias apresentou lesões crostosas e de aspecto verrucoso na superfície dorsal das patas. Havia, também, nódulos de mesmo aspecto na pálpebra esquerda e na cera. A ave morreu após 15 dias de sua chegada ao NURFS e foi necropsiada no Laboratório Regional de Diagnóstico da Faculdade de Veterinária da Universidade Federal de Pelotas (LRD/UFPel). Histologicamente, as lesões verrucosas caracterizavam-se por hiperplasia do epitélio e nas células das camadas basal, espinhosa, granular e córnea havia corpúsculos de inclusão intracitoplasmáticos do tipo Bollinger. Na microscopia eletrônica foram visualizadas partículas virais características de 
pox vírus, incluindo Bubo virginianus como um hospedeiro do vírus. Havia, ainda, infiltrado inflamatório de células mononucleares e focos de colônias bacterianas na derme. Nos pulmões havia congestão e presença de granulomas com hifas fúngicas, que pela técnica de Grocott, apresentaram ramificação dicotômica compatível com Aspergillus spp., identificado na cultura como $A$. fumigatus. 0 diagnóstico de infecção por avipoxvirus pode contribuir para estudos relacionados com a ocorrência desta doença nas populações de vida livre e como informação auxiliar para o manejo e conservação desta espécie. Sugere-se, ainda, a inclusão do uso de raios-X nos protocolos de centros de reabilitação como o diagnostico de aspergilose em aves rapinantes com bom estado corporal, porém incapazes de voar.

TERMOS DE INDEXAÇÃO: Pox vírus aviário, bouba aviária, Aspergillus fumigatus, aspergilose, Bubo virginianus, coruja jacurutu.

\section{INTRODUÇÃO}

A bouba aviária é causada por um avipoxvirus (APV) da família Poxviridae. Trata-se de uma doença altamente contagiosa conhecida por epitelioma contagioso das aves. Apresenta duas formas clínicas, sendo a mais diagnosticada a forma cutânea, que é caracterizada por lesões crostosas e nodulares no epitélio, principalmente onde não existem penas, como a cera, pálpebras, crista, barbela e patas. A forma visceral, também conhecida por wetpox, acomete a mucosa da boca, esôfago e trato respiratório superior causando a formação de placas fibrinonecróticas que dificultam a alimentação e a respiração (Tripathy \& Redd 2008).

A doença tem ocorrência mundial (Van Riper \& Forrester 2007) e a contaminação é facilitada em virtude de o vírus permanecer muito tempo no ambiente e por ser resistente a desinfetantes comuns (Tripathy \& Redd 2008). Lesões na pele causadas por vetores como mosquitos e piolhos hematófagos são porta de entrada para a contaminação com o vírus (Proctor \& Owens 2000). Outra condição que favorece a disseminação do vírus é a superpopulação (Wheeldon et al. 1985, Tripathy \& Redd 2008).

A doença já foi descrita em mais de 20 famílias de aves. No Brasil é descrita em passeriformes silvestres de criação doméstica, como Cyanoloxia brissonii (azulão), Sicalis flaveola (canário-da-terra-verdadeiro) (Van Riper \& Forrester 2007) e em algumas espécies de aves de vida livre como Tyto alba (coruja de igreja) (Vargas et al. 2011) e Dendrocygna autumnalis (marreca-cabocla) (Pereira et al. 2014). Dados relativos à incidência e distribuição desta doença nas populações de aves silvestres ainda são escassos, especialmente na ordem Strigiformes que engloba as corujas (Vargas et al. 2011).

Por sua vez a aspergilose é uma micose oportunista que em aves causa pneumonia granulomatosa e aerossaculite, podendo se disseminar por todo organismo (Orosz 2000). A espécie mais comumente isolada de Aspergillus em aves silvestres é $A$. fumigattus, porém outras espécies como $A$. flavus, A. niger, A. glaucus, A. nidulans podem causar a doença (Joseph 2000, Orosz 2000). Esta doença tem uma maior prevalência em aves que estão em centros de recuperação, provavelmente devido a imunossupressão do cativeiro (Xavier et al. 2006). Por ser um organismo ubíquo no ambiente sua erradicação torna-se difícil. Logo, esta doença normalmente não acontece de forma isolada e sua associação com outras enfermidades é comum (Greenacre et al. 1992).

\section{MATERIAL E MÉTODOS}

Um espécime macho, adulto de Bubo virginianus foi encaminhado pelo 2 o Pelotão de Rio Grande do Policiamento Ambiental ao Núcleo de Reabilitação da Fauna Silvestre (NURFS-CETAS/UFPEL) em dezembro de 2014. Foi realizado o exame clínico e tratamento de suporte. A coruja morreu 15 dias após sua entrada, sendo necropsiada logo após a morte. Amostras de todos os órgãos foram coletadas, fixadas em formalina tamponada a $10 \%$, processadas rotineiramente e coradas por hematoxilina e eosina para análise histológica. Pequenas porções de pele da pálpebra inferior direita e das patas foram fixados em glutaraldeído a $2 \%$ com paraformaldeído a $2 \%$, em $0,4 \mathrm{M}$ de solução tampão de cacodilato (pH 7,4). Os blocos foram pós-fixados em 1\% tetróxido de ósmio tamponado em cacodilato de sódio $0,4 \mathrm{M}(\mathrm{pH} 7,4)$ e embebidos em Epon 812. Lâminas com cortes semifinos foram coradas com azul de metileno. As seções ultrafinas foram coradas com citrato de chumbo e acetato de uranila e examinadas ao microscópio eletrônico (EM 109 Zeiss).

Amostras de fígado, saco aéreo e pulmão foram encaminhadas ao laboratório de microbiologia do LRD/UFPEL e semeados em Ágar Sabouraud e Ágar Malte a $37^{\circ} \mathrm{C}$ por sete dias, acrescidos de cloranfenicol, para possível isolamento de fungos. Os isolados foram repicados em Ágar Czapeck a $25^{\circ} \mathrm{C}$ por sete dias e o exame direto da colônia foi realizado utilizando o corante lactofenol azul algodão. Fragmentos de rim, fígado e pulmão foram submetidos à coloração de Grocott.

\section{RESULTADOS}

Ao dar entrada no NURFS, a coruja estava alerta, porém com incapacidade de voo, sendo colocada em um recinto com serragem de Pinus spp., poleiros de diâmetros variados e alimentação à vontade. Depois de três dias de sua entrada no referido centro, a ave começou a apresentar hiperqueratose nas patas, evoluindo para lesões constituídas de massas firmes de aspecto crostoso e verrucoso, de coloração amarronzada que sobressaiam na superfície dorsal dos membros inferiores, estendendo-se até a articulação tibiotarso-tarsometatársica (Fig.1). Em decorrência destas lesões a coruja começou a apresentar claudicação e dificuldade de locomoção. Desenvolveu, também, formações verrucosas na pálpebra inferior esquerda e na cera (Fig.2). As lesões das patas foram tratadas com solução tópica de Thuya occidentalis associada com fenol e ácido acetil salicílico, sendo estas limpas duas vezes ao dia com solução de clorexidina a $4 \%$. Doze dias após o início da hiperqueratose a ave morreu.

Durante a necropsia, as lesões externas supracitadas, ao corte mostravam-se firmes e exuberantes, havia nódulos branco-amarelados nos pulmões medindo aproximadamente $5 \mathrm{~mm}$. Foi observado, também, um nódulo de mesmo aspecto no fígado. No pulmão e no saco aéreo torácico esquerdo havia um nódulo de aproximadamente $20 \mathrm{~mm}$ de diâmetro que se estendia até o ápice do rim de mesmo lado. Ao corte o nódulo era firme e cavitado, com as paredes recobertas com placas amareladas e de aspecto caseoso.

Histologicamente, na pele, havia hiperplasia do epitélio das falanges e da região da articulação tíbiotarso-tarsome- 


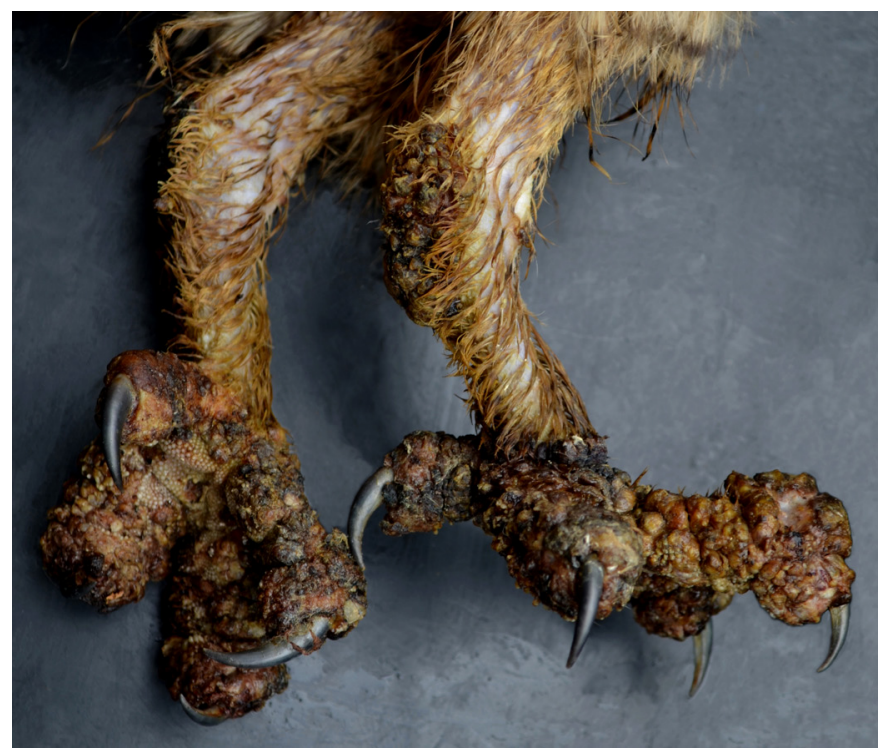

Fig.1. Infecção por Pox vírus e Aspergillus fumigatus em Bubo virginianus. Presença de nódulos proliferativos e verrucosos que sobressaem na pele das patas e da região tíbio-tarso-tarso-metatársica.

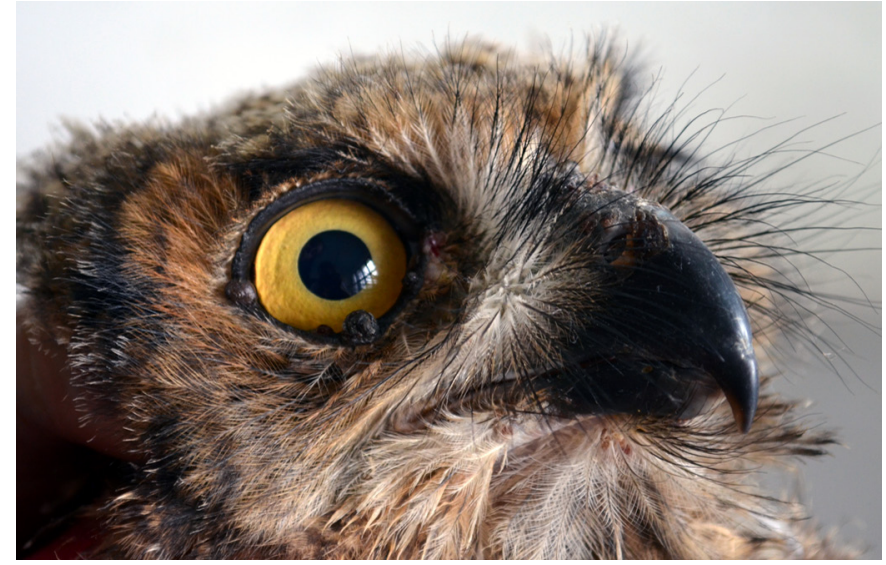

Fig.2. Infecção por Pox vírus e Aspergillus fumigatus em Bubo virginianus. Presença de nódulos na pálpebra esquerda e hiperqueratose na cera.

tatársica e corpúsculos de inclusão intracitoplasmáticos eosinofílicos do tipo Bollinger na camada basal, espinhal, granulosa e córnea (Fig.3). Na microscopia eletrônica em cortes selecionados dos corpúsculos de inclusão, havia partículas virais grandes medindo $200 \mathrm{~nm}$ de formato bicôncavo, envolvidos por envelope (Fig.4).

Havia, ainda, infiltrado inflamatório de células mononucleares, congestão, trombos e focos de colônias bacterianas na derme. Nos pulmões observou-se congestão e granulomas com hifas fúngicas que pela técnica de Grocott apresentaram ramificação dicotômica compatível com Aspergillus spp. (Fig.5), identificado na cultura como A. fumigatus.

\section{DISCUSSÃO}

O diagnóstico de infecção por pox vírus aviário (APV) foi realizado pelas lesões macroscópicas, histológicas e confirmado pela microscopia eletrônica. As lesões eram se- melhantes às observadas em outros relatos desta infecção em corujas (Tripathy \& Redd 2008, Vargas et al. 2011). Nos rapinantes, principalmente os Strigiformes, têm sido relatadas lesões mais exuberantes do que em outras ordens de aves (Deern et al. 1997, Friend \& Franson 1999). As lesões apresentam-se principalmente nos olhos e nas patas, o que pode impedi-las de caçar e apreender as suas presas deixando-as vulneráveis (Pearson et al. 1975). Além das lesões características de APV a coruja apresentava, também, múltiplos granulomas fúngicos associados a A. fumigatus em diversos órgãos. De acordo com Rupley (1999), conforme o aspecto da lesão de aspergilose pode-se estimar a 'idade' da lesão, sendo as em formato de nódulo mais recentes que

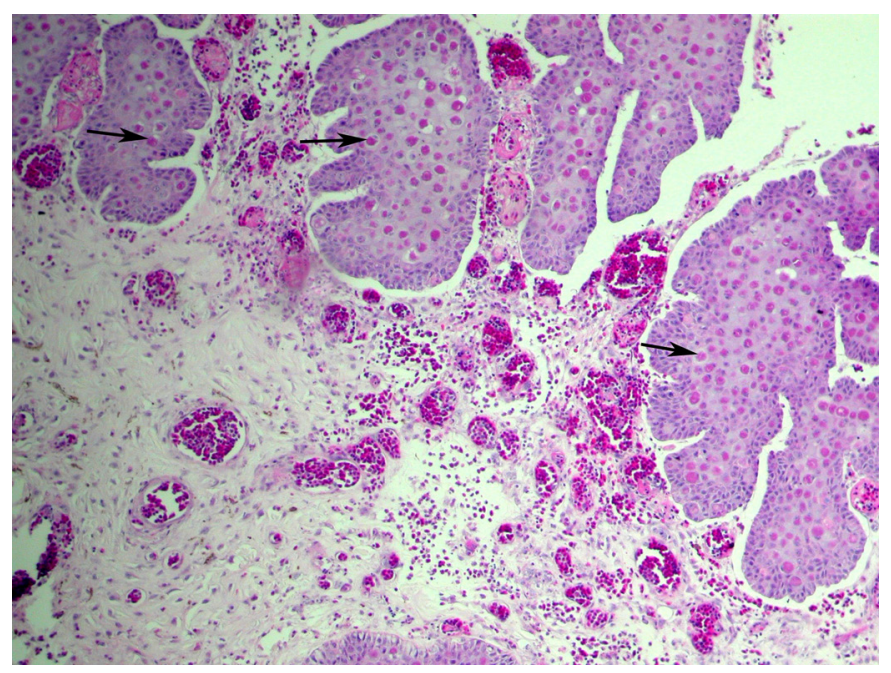

Fig.3. Infecção por Pox vírus e Aspergillus fumigatus em Bubo virginianus. Na pele das patas há numerosos corpúsculos de Bollinger em formato de anel eosinofílico sólido (setas) HE, $100 x$.

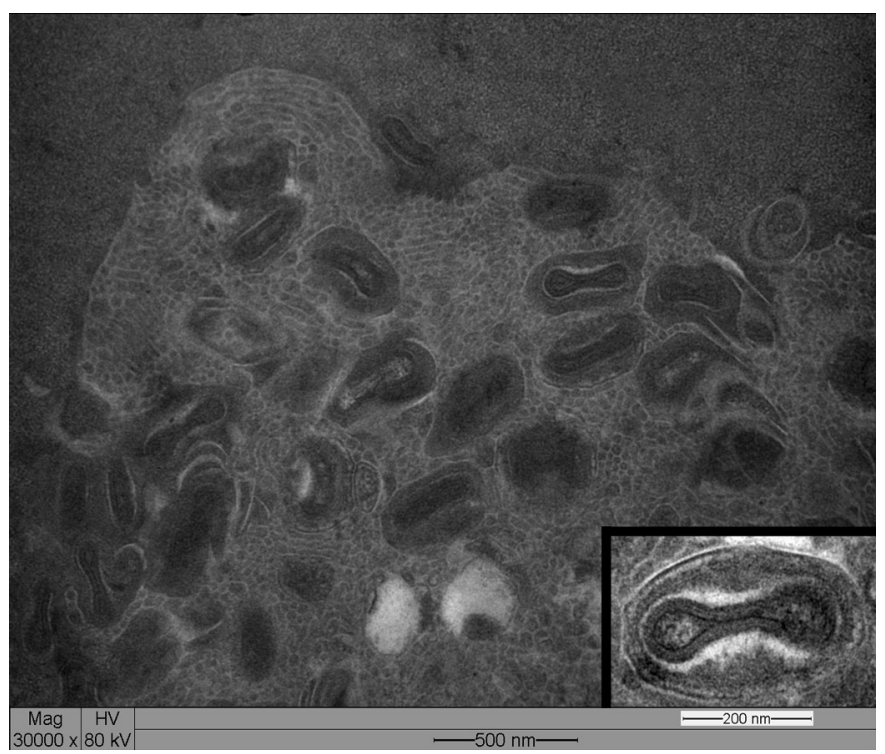

Fig.4. Infecção por Pox vírus e Aspergillus fumigatus em Bubo virginianus. Pele. Vesícula contendo partículas víricas típicas de pox vírus aviário. Barra $=500 \mathrm{~nm}$. Inset: observa-se núcleo eletrodenso bicôncavo, recoberto por uma camada exterior de lipoproteína. Barra $=200 \mathrm{~nm}$. 


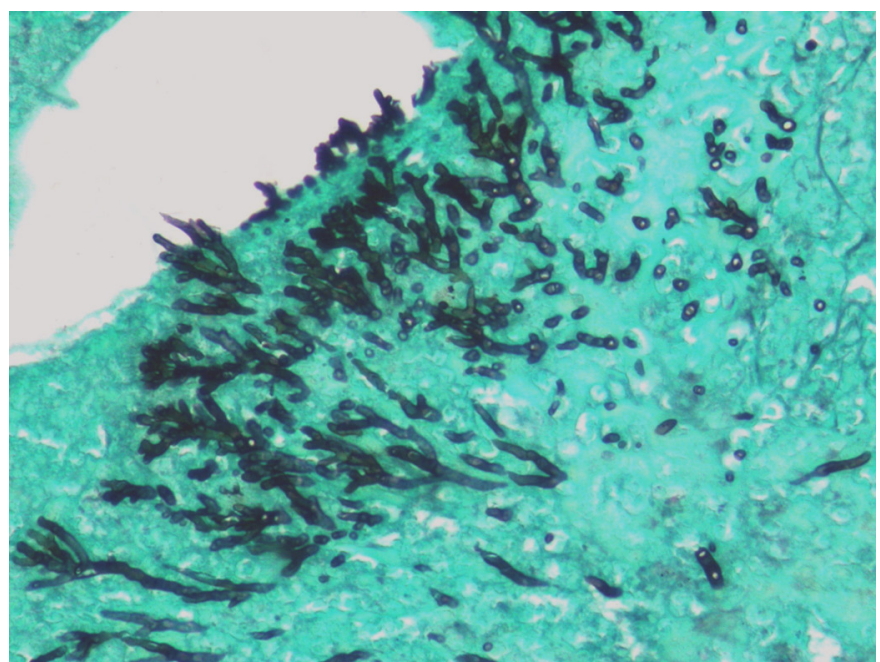

Fig.5. Infecção por Pox vírus e Aspergillus fumigatus em Bubo virginianus. Pulmão. Hifas com ramificação dicotômica irradiando para o parabrônquio compatível com Aspergillus sp. Grocott. 200x.

as em formato de placa. No presente caso os granulomas tinham ambas as formas o que sugere que esta coruja já estava infectada ao chegar ao NURFS/UFPel.

Apesar de a ave estar em boa condição corporal, a incapacidade de voar pode ser atribuída a gravidade das lesões de aspergilose no trato respiratório, o qual não fornecia aporte suficiente de oxigenação para o voo. A aspergilose é uma micose oportunista que acomete diversas espécies de aves (Andreatti-Filho 2009), sendo considerada uma doença que acomete seres imunodeficientes (Rupley 1999). Corriqueiramente associa-se esta doença ao cativeiro, porém, neste caso, a ave encontrava-se em vida livre e apresentou aspergilose com lesões em diferentes estágios de evolução sugerindo uma condição deficiente do sistema imune do Jacurutu prévia ao cativeiro. 0 quadro clínico de aspergilose não diagnosticada previamente devido a ausência de sinais clínicos relevantes pode explicar as lesões disseminadas da forma cutânea da bouba aviária e posterior morte da ave.

0 tempo de incubação da bouba aviária varia conforme as espécies (Tripathy \& Redd 2008) e em rapinantes esta informação não está bem definida na literatura, já que casos desta doença em Strigiformes de vida livre são raros. Algumas tentativas de infecção experimental em $B$. virginianus foram feitas a fim de elucidar estas questões, porém não foram exitosas, sugerindo que esta espécie poderia apenas se contaminar com um vírus específico (Irons 1934, Pearson et al. 1975, Wheeldon et al. 1985, Deern et al. 1997). Pouco se sabe sobre o status sanitário das populações de vida livre e quais as possíveis doenças de etiologias diversas que possam interferir no sistema imune predispondo ao acometimento por doenças oportunistas como a aspergilose.

O B. virginianus é a espécie de coruja mais difundida geograficamente das Américas, sendo encontrada desde as montanhas rochosas do Canadá até a patagônia Argentina (Sick 1997). Sua distribuição contrasta com as poucas informações sobre as doenças que podem acometer esta espécie em especial a infecção por APV. Por esta razão é difícil determinar qual é o espectro de hospedeiros deste gênero e a importância desta doença nas populações de vida livre já que casos de infecção por este vírus em $B$. virginianus não têm sido descritos na literatura.

Levando em consideração a forma de transmissão do vírus podemos considerar o $B$. virginianus como um hospedeiro em potencial do APV, não se descartando a possibilidade de que o APV possa estar circulando em animais de vida livre. Os resultados aqui apresentados podem contribuir para estudos relacionados com o impacto desta doença nas populações de vida livre e como informação auxiliar para o manejo e conservação desta espécie. Sugere-se ainda a inclusão do uso de raios-X nos protocolos de centros de reabilitação como um exame rápido e fácil para o descarte de aspergilose em aves rapinantes com bom estado corporal e incapacidade de voo.

Agradecimentos.- Os autores agradecem à Prof $\stackrel{\text { a }}{\text {. Dra }}$ Daniela Brayer Pereira do Departamento de Parasitologia e Microbiologia, Instituto de Biologia, Universidade Federal de Pelotas pelo isolamento do fungo Aspergillus fumigatus.

\section{REFERÊNCIAS}

Andreatti-Filho R.L. 2009. Enfermidades micóticas, p.805-818. In: Berchieri Jr A., Silva E.N., Di Fábio J., Sesti L. \& Zuanaze M.A.F. (Eds), Doenças das Aves. $2^{-}$ed. FACTA, Campinas.

Deern S.L., Heard D.J. \& Fox J.H. 1997. Avian pox in eastern screech owls and barred owls from Florida. J. Wildl. Dis. 33:323-332.

Friend M. \& Franson J.C. 1999. Avian pox, p.163-170. In: Ibid. (Eds), Field Manual of Wildlife Diseases. USGS Science for a Changing World, Madison, CA. 438p.

Greenacre C.B., Latimer K.S. \& Ritchie B.W. 1992. Leg paresis in a black palm cockatoo (Probosciger aterrimus) caused by aspergillosis. J. Zoo Wildl. Med. 23:122-126.

Irons V. 1934. Cross-species transmission studies with different strainns of bird-pox. Am. J. Hygiene 20:329-351.

Joseph V. 2000. Aspergillosis in raptors. Seminars in Avian and Exotic Pet Medicine, W.B. Saunders, 9(2):66-74.

Orosz S.E. 2000. Overview of aspergillosis: pathogenesis and treatment options. Seminars in Avian and Exotic Pet Medicine, W.B. Saunders, 9(2):59-65.

Pearson G.L., Pass D.A. \& Beggs E.C. 1975, Fatal pox infection in a roughlegged hawk. Paper 112. USGS Northern Prairie Wildlife Research Center.

Pereira W., Martins G.A., Monger S., Moraes L., Queiroz D. \& Souza A. 2014. Lesões cutâneas tipo tumorais associadas à infecção por avipoxvirus em uma marreca-cabocla (Dendrocygna autumnalis). Ciênc. Anim. Bras. 15(2):234-238.

Proctor H. \& Ownes I. 2000. Mites and birds: diversity, parasitism and coevolution. Trends Ecol. Evol. 15(9):358-364.

Rupley A. 1999. Manual de Clínica Aviária. Roca, São Paulo. 582p.

Sick H. 1997. Ornitologia Brasileira. Nova Fronteira, Rio de Janeiro.

Tripathy D.N. \& Reed W.M. 2008. Pox, p.583-596. In: Saif Y.M. (Ed.), Diseases of Poultry. 12th ed. Iowa State University Press, Ames.

Van Riper III C. \& Forrester D.J. 2007. Avian pox, p.131-176. In: Thomas N.J., Hunter D.B. \& Carter Atkinson T. (Eds), Infectious Diseases of Wild Birds. Blackwell Publishing, Iowa.

Vargas G.D., Albano A.P., Fischer G., Hübner S., Sallis S.E., Nunes C.F., Raffi M.B. \& Soares M.P. 2011. Avian pox virus infection in a common barn owl (Tyto alba) in southern Brazil. Pesq. Vet. Bras. 31(7):620-622.

Wheeldon E.B., Sedgvick C.J. \& Schulz T.A. 1985. Epomitic of avian pox in a raptor rehabilitation center. J. Am. Vet. Med. Assoc. 187:1202-1204.

Xavier M.O., Leite A.T.M., Soares M.P., Gama-Osório L., Martins A., Albano A.P., Carapeto L.P., Oliveira-Nobre M., Silva-Filho R.P. \& Meireles M.C.A. 2006. Aspergilose em pingüim-de-magalhães (Spheniscus magellanicus). Vet. Zootec. 13(1):28-32. 